\title{
HIMPUNAN KOMPAK PADA RUANG METRIK FUZZY
}

\author{
SENDY AIWA PRATAMA, JENIZON, HARIPAMYU \\ Program Studi S1 Matematika, \\ Fakultas Matematika dan Ilmu Pengetahuan Alam, Universitas Andalas, \\ Kampus UNAND Limau Manis Padang, Indonesia, \\ email : ap_sendy@yahoo.com, jenizon@sci.unand.ac.id,haripamyu@sci.unand.ac.id
}

Diterima 15 September 2020 Direvisi 14 Oktober 2020 Dipublikasikan 21 Oktober 2020

\begin{abstract}
Abstrak. Himpunan kompak adalah suatu himpunan yang setiap selimut bukanya memiliki subselimut berhingga. Pendefinisian ruang metrik fuzzy dapat menggunakan pendefinisian oleh George dan Veeramani, yaitu dengan menggunakan bantuan norm- $t$ kontinu. Pada tulisan ini ditunjukkan pendefinisian dan sifat himpunan kompak pada ruang metrik fuzzy serta hubungan himpunan kompak dan barisan pada ruang metrik fuzzy.
\end{abstract}

Kata Kunci: Subselimut Berhingga, Himpunan Kompak, Ruang Metrik Fuzzy, Norm-t Kontinu, Selimut Buka

\section{Pendahuluan}

Himpunan fuzzy (himpunan kabur) diperkenalkan oleh Zadeh [7] pada tahun 1965. Teori ini dikembangkan dengan tujuan untuk menyelesaikan permasalahan yang mengandung ketidakpastian, seperti pengambilan keputusan. Himpunan fuzzy merupakan suatu himpunan yang memiliki nilai keanggotaan pada selang [0,1]. Nilai keanggotaan pada himpunan fuzzy menunjukkan tingkat kekaburan dari suatu objek.

Sekarang ini banyak matematikawan yang mempelajari teori matematika lain yang dipadukan dengan teori himpunan fuzzy, salah satunya adalah konsep ruang metrik yang menghasilkan ruang metrik fuzzy. Pada tahun 1994, George dan Veeramani mendefinisikan ruang metrik fuzzy dengan menggunakan bantuan normt kontinu. Selanjutnya, banyak matematikawan menggunakan pendefinisian tersebut dalam mempelajari dan membahas konsep ruang metrik fuzzy. Pembahasan mengenai ruang metrik fuzzy dan sifat-sifatnya banyak dilakukan. Pada artikel ini akan dibahas kembali mengenai himpunan kompak di ruang metrik fuzzy yang telah dikaji oleh Al-Mayahi dan kawan-kawan [5]. 
340 Sendy Aiwa Pratama dkk

\section{Landasan Teori}

\subsection{Himpunan Fuzzy}

Pada konsep himpunan fuzzy, suatu himpunan dikaitkan dengan suatu fungsi (fungsi keanggotaan) yang menyatakan derajat kesesuaian antara unsur-unsur pada himpunan tersebut dengan suatu ketentuan yang menjadi syarat keanggotaan dari himpunan tersebut.

Definisi 2.1. [7] Misalkan X adalah himpunan objek-objek, maka suatu Himpunan Fuzzy $F$ atas himpunan $X$ didefinisikan sebagai:

$$
F=\{(x, \mu(x)) \mid x \in X\}
$$

dimana $\mu: X \rightarrow[0,1]$ disebut fungsi keanggotaan $F$ atas $X$.

\subsection{Ruang Metrik Fuzzy}

Definisi 2.2. [4] Suatu operasi biner $*:[0,1] \times[0,1] \rightarrow[0,1]$ disebut norm-t apabila kondisi berikut dipenuhi:

(1) * bersifat asosiatif dan komutatif;

(2) $a * 1=a$ untuk setiap $a \in[0,1]$;

(3) Jika $a \leq c$ dan $b \leq d$ maka $a * b \leq c * d$, untuk setiap $a, b, c, d \in[0,1]$.

Selanjutnya $*$ adalah norm-t kontinu jika * kontinu.

Contoh 2.3. [4] Didefinisikan suatu operasi biner $*:[0,1] \times[0,1] \rightarrow[0,1]$ dengan $a * b=a . b$ untuk setiap $a, b \in[0,1]$. Dapat dibuktikan bahwa operasi $*$ tersebut merupakan norm-t kontinu.

Definisi 2.4. [6] Misalkan $X$ adalah suatu himpunan tak kosong, * adalah suatu norm-t kontinu, dan $M$ adalah suatu himpunan fuzzy pada $X \times X \times(0, \infty) .(X, M, *)$ dikatakan suatu ruang metrik fuzzy apabila untuk setiap $x, y, z \in X$ dan $s, t \in(0, \infty)$ berlaku kondisi berikut:

(1) $M(x, y, t)>0$;

(2) $M(x, y, t)=1 \Leftrightarrow x=y$;

(3) $M(x, y, t)=M(y, x, t)$;

(4) $M(x, y, t) * M(y, z, s) \leq M(x, z, t+s)$;

(5) Fungsi $M(x, y, \cdot):(0, \infty) \rightarrow[0,1]$ kontinu.

Jika $(X, M, *)$ adalah ruang metrik fuzzy, maka $(M, *)$ disebut suatu merik fuzzy di $X$. Jika $M$ adalah suatu himpunan fuzzy pada $X \times X \times[0, \infty)$ maka kondisi (1) menjadi $M(x, y, 0)=0$.

Contoh 2.5. [3] Misalkan $X=\mathbb{N}$ dan norm-t kontinu diberikan pada Contoh 2.3. Misalkan $M$ adalah fungsi keanggotaan pada $X \times X \times(0, \infty)$ yang didefinisikan sebagai:

$$
M(x, y, t)= \begin{cases}\frac{x}{y}, & \text { jika } x \leq y \\ \frac{y}{x}, & \text { jika } x \leq y\end{cases}
$$


untuk setiap $x, y \in X$ dan $t>0$. Maka $(X, M, *)$ adalah ruang metrik fuzzy.

Definisi 2.6. [6] Misalkan $(X, M, *)$ adalah ruang metrik fuzzy dan misalkan $r \in$ $(0,1), t>0$ dan $x \in X$. Himpunan $B_{M}(x, r, t)=\{y \in X \mid M(x, y, t)>1-r\}$ disebut bola buka dengan pusat $x$ dan jari-jari $r$ dengan mempertimbangkan $t$.

Definisi 2.7. [3] Suatu subhimpunan A dari ruang metrik fuzzy dikatakan buka bila untuk setiap titik $a \in A$, terdapat $r \in(0,1)$ dan $t>0$ sedemikian sehingga $B_{M}(a, r, t) \subseteq A$.

Teorema 2.8. [3] Pada ruang metrik fuzzy setiap bola buka adalah himpunan buka.

Bukti. Perhatikan bola buka $B_{M}(x, r, t)$. Misalkan $y \in B_{M}(x, r, t)$ maka $M(x, y, t)>1-r$. Karena $M(x, y, t)>1-r$, menurut pernyataan Maggie Aphane dalam [3] bahwa jika dimisalkan $(X, M, *)$ adalah ruang metrik fuzzy dan $x, y \in X$, $t>0$ dan $r \in(0,1)$, maka bila mana $M(x, y, t)>1-r$, terdapat $t_{0}$ dengan $0<t_{0}<t$ sedemikian sehingga $M\left(x, y, t_{0}\right)>1-r$. Misalkan $M\left(x, y, t_{0}\right)=r_{0}$ maka $r_{0}>1-r$. Akibatnya terdapat $r_{1} \in(0,1)$ sedemikian sehingga $r_{0}>1-r_{1}>1-r$. Perhatikan bahwa untuk $r_{0}>1-r_{1}$ terdapat $r_{2} \in(0,1)$ sedemikian sehingga $r_{0} * r_{2}>1-r_{1}$.

Diberikan bola buka $B\left(y, 1-r_{2}, t-t_{0}\right)$ dan $z \in B\left(y, 1-r_{2}, t-t_{0}\right)$, maka $M\left(y, z, t-t_{0}\right)>r_{2}$. Dengan menggunakan kondisi 4 pada Definisi 2.4, diperoleh $M(x, z, t)>1-r_{1}$. Karena $1-r_{1}>1-r$, maka diperoleh $M(x, z, t)>1-r$ sehingga $z \in B(x, r, t)$. Oleh karena itu, $B\left(y, 1-r_{1}, t-t_{0}\right) \subseteq B(x, r, t)$.

Definisi 2.9. [1] Suatu barisan $X=\left(x_{n}\right)$ di $\mathbb{R}$ dikatakan konvergen ke $x \in \mathbb{R}$, atau $x$ dikatakan limit dari $\left(x_{n}\right)$, jika untuk setiap $\varepsilon>0$ terdapat bilangan asli $K(\varepsilon)$ sedemikian sehingga untuk setiap $n \geq K(\varepsilon)$, berlaku $\left|x_{n}-x\right|<\varepsilon$.

Definisi 2.10. [5] Misalkan $(X, M, *)$ adalah ruang metrik fuzzy, maka barisan $\left(x_{n}\right)$ di $X$ dikatakan konvergen ke $x$ di $X$ jika untuk setiap $r \in(0,1)$ dan untuk setiap $t>0$, terdapat $k \in \mathbb{Z}^{+}$sehingga $M\left(x_{n}, x, t\right)>1-r$ untuk semua $n \geq k$ (atau ekuivalen dengan

$$
\lim _{n \rightarrow \infty} M\left(x_{n}, x, t\right)=1
$$

Contoh 2.11. Dari Contoh 2.5 dan dengan $X=\mathbb{R}^{+}$, maka barisan $\left(1-\frac{1}{n}\right)$, untuk $n=1,2, \cdots$ adalah barisan konvergen di $(X, M, *)$.

Definisi 2.12. [5] Misalkan $(X, M, *)$ adalah ruang metrik fuzzy, maka barisan $\left(x_{n}\right)$ di $X$ dikatakan barisan Cauchy jika untuk setiap $r \in(0,1)$ dan untuk setiap $t>0$, terdapat $k \in \mathbb{Z}^{+}$sehingga $M\left(x_{n}, x_{m}, t\right)>1-r$ untuk semua $n, m \geq k$ (atau ekuivalen dengan

$$
\lim _{n, m \rightarrow \infty} M\left(x_{n}, x_{m}, t\right)=1 .
$$

Definisi 2.13. [5] Misalkan $(X, M, *)$ adalah suatu ruang metrik fuzzy. Suatu subhimpunan $A$ dari $X$ dikatakan tertutup jika setiap barisan $\left(x_{n}\right)$ di $A$ konvergen ke $x$ dimana $x \in A$. 
Definisi 2.14. [5] Misalkan $(X, M, *)$ adalah ruang metrik fuzzy. Suatu subhimpunan $A$ dari $X$ dikatakan terbatas jika terdapat $t>0$ dan $0<r<1$ sehingga $M(x, y, t)>1-r$, untuk setiap $x, y \in A$.

Definisi 2.15. [5] Misalkan $(X, M, *)$ dan $(Y, M, *)$ adalah ruang metrik fuzzy. Fungsi $f: X \rightarrow Y$ dikatakan kontinu di $x_{0} \in X$ jika untuk setiap $r \in(0,1)$ dan $t>0$ terdapat $r_{1} \in(0,1)$ dan $s>0$ sehingga untuk setiap $x \in X$, bila mana $M\left(x, x_{0}, s\right)>1-r_{1}$ maka $M\left(f(x), f\left(x_{0}\right), t\right)>1-r$.

\subsection{Himpunan Kompak}

Definisi 2.16. [1] Misalkan A adalah subhimpunan dari $\mathbb{R}$. Suatu selimut buka dari $A$ adalah koleksi $\mathcal{G}=\left\{G_{\alpha}\right\}$ dari himpunan buka di $\mathbb{R}$ (dengan $G_{\alpha}$ merupakan himpunan buka) yang gabungannya memuat $A$, yaitu $A \subseteq \bigcup_{\alpha} G_{\alpha}$. Jika $\mathcal{G}^{\prime}$ adalah subkoleksi himpunan-himpunan dari $\mathcal{G}$ sehingga gabungan dari himpunanhimpunan di $\mathcal{G}^{\prime}$ juga memuat $A$, maka $\mathcal{G}^{\prime}$ disebut subselimut dari $\mathcal{G}$. Jika $\mathcal{G}^{\prime}$ terdiri dari himpunan-himpunan berhingga, maka $\mathcal{G}^{\prime}$ disebut subselimut berhingga di $\mathcal{G}$.

Contoh 2.17. [1] Jika $A=[1, \infty)$, maka koleksi $\mathcal{G}=\{(n-1, n+1): n \in \mathbb{N}\}$ adalah selimut buka di A.

Definisi 2.18. [1] Suatu subhimpunan $K$ dari $X$ dikatakan kompak jika setiap selimut buka di K memiliki subselimut berhingga.

Contoh 2.19. [1] Misalkan $K=\left\{x_{1}, x_{2}, \cdots, x_{n}\right\}$ merupakan suatu subhimpunan berhingga di $\mathbb{R}$. Jika $\mathcal{G}=\left\{G_{\alpha}\right\}$ adalah sebuah selimut buka di K, maka untuk setiap $x_{i}$ terdapat pada beberapa himpunan $G_{\alpha_{i}}$ di $\mathcal{G}$. Selanjutnya, gabungan dari himpunan-himpunan di koleksi $\left\{G_{\alpha_{1}}, G_{\alpha_{2}}, \cdots, G_{\alpha_{n}}\right\}$ mengandung $K$ sehingga gabungan himpunan-himpunan tersebut adalah subselimut berhingga dari $\mathcal{G}$. Karena $\mathcal{G}$ sebarang, maka himpunan berhingga $K$ adalah kompak.

Definisi 2.20. [2] Suatu subhimpunan A dari $\mathbb{R}^{n}$ adalah kompak jika setiap barisan $\left(a_{k}\right)_{k=1}^{\infty}$ di A memiliki subbarisan konvergen $\left(a_{k_{i}}\right)_{i=1}^{\infty}$ dengan limit

$$
a=\lim _{i \rightarrow \infty} a_{k_{i}}
$$

di A.

Contoh 2.21. [2] Ambil suatu himpunan [0,1]. Barisan $1, \frac{1}{2}, \frac{1}{3}, \cdots$ berada pada himpunan dan konvergen ke 0 , yang mana 0 termasuk ke dalam himpunan $[0,1]$. Karena setiap subbarisan juga akan konvergen ke 0 , maka subbarisan dari $1, \frac{1}{2}, \frac{1}{3}, \cdots$ konvergen ke anggota himpunan $[0,1]$. Jadi himpunan ini adalah kompak.

\section{Pembahasan}

Definisi 3.1. [5] Misalkan $(X, M, *)$ suatu ruang metrik fuzzy dan $A \subset X$. Himpunan A dikatakan himpunan kompak jika setiap selimut buka memiliki subselimut berhingga. 
Misalkan $(X, M, *)$ adalah suatu ruang metrik fuzzy dan $X$ adalah himpunan kompak, dapat dikatakan bahwa $(X, M, *)$ adalah suatu ruang metrik fuzzy kompak.

Contoh 3.2. Misalkan $A=\left\{x_{1}, x_{2}, \cdots, x_{n}\right\}$ merupakan suatu subhimpunan berhingga di ruang metrik fuzzy $(X, M, *)$. Jika $\mathcal{B}=\left\{B_{M}(x, r, t): x \in A\right\}$ adalah selimut buka di $(X, M, *)$, maka untuk setiap $x_{i}$ terdapat beberapa himpunan $B_{M}\left(x_{i}, r, t\right)$ di $\mathcal{B}$. Selanjutnya, gabungan dari himpunan-himpunan di koleksi $\left\{B_{M}\left(x_{1}, r, t\right), B_{M}\left(x_{2}, r, t\right), \cdots, B_{M}\left(x_{n}, r, t\right)\right\}$ mengandung $A$ sehingga gabungan himpunan-himpunan tersebut adalah subselimut berhingga dari $\mathcal{B}$. Karena $\mathcal{B}$ sebarang, maka himpunan $A$ adalah kompak.

Teorema 3.3. [3] Setiap subhimpunan kompak A di suatu ruang metrik fuzzy adalah terbatas.

Bukti. Diberikan $A$ suatu subhimpunan kompak di ruang metrik fuzzy, $t>0$ dan $0<r<1$. Misalkan $\left\{B_{M}(x, r, t): x \in A\right\}$ suatu selimut buka di $A$. Karena $A$ adalah kompak, maka terdapat subselimut berhingga $\left\{B_{M}\left(x_{i}, r, t\right): x_{i} \in A ; i=1,2, \cdots, n\right\}$ sehingga $A \subseteq \bigcup_{i=1}^{n} B_{M}\left(x_{i}, r, t\right)$. Misalkan $x, y \in A$ sehingga $x \in B_{M}\left(x_{i}, r, t\right)$ dan $y \in B_{M}\left(x_{j}, r, t\right)$ untuk beberapa $i, j$. Oleh karena itu, $M\left(x, x_{i}, t\right)>1-r$ dan $M\left(y, x_{j}, t\right)>1-r$. Kemudian, misalkan $\alpha=\min \left\{M\left(x_{i}, x_{j}, t\right): 1 \leq i, j \leq n\right\}$, maka $\alpha>0$. Selanjutnya, dengan menggunakan kondisi 4 pada Definisi 2.4, diperoleh $M(x, y, 3 t) \geq(1-r) * \alpha *(1-r)$. Misalkan $t^{\prime}=3 t$ dan $(1-r) * \alpha *(1-r)>1-s$, untuk $0<s<1$ sehingga $M\left(x, y, t^{\prime}\right)>1-s$, untuk setiap $x, y \in A$. Oleh karena itu, $A$ adalah terbatas.

Teorema 3.4. [5] Setiap himpunan berhingga pada ruang metrik fuzzy adalah kompak.

Bukti. Ambil $A=\left\{a_{1}, a_{2}, \cdots, a_{n}\right\}$ adalah sebarang himpunan berhingga pada ruang metrik fuzzy dengan $\left\{B_{M}(a, r, t): a \in A\right\}$ adalah selimut buka di A, untuk setiap $r \in(0,1), t>0$, sehingga $A \subseteq \bigcup_{a \in A} B_{M}(a, r, t)$. Karena $\left\{B_{M}(a, r, t): a \in A\right\}$ adalah selimut buka di A, maka untuk setiap $a_{i} \in A$ terdapat $\left\{B_{M}\left(a_{i}, r, t\right): a_{i} \in\right.$ $A$ \} untuk $i=1,2, \cdots, n$, sehingga $a_{i} \in \bigcup_{a_{i} \in A} B_{M}\left(a_{i}, r, t\right)$. Maka terdapat $a_{i} \in$ $B_{M}\left(a_{i}, r, t\right)$ untuk beberapa i. Karenanya $B_{M}\left(a_{i}, r, t\right)$ adalah subselimut berhingga sehingga $A \subseteq \bigcup_{a_{i} \in A} B_{M}\left(a_{i}, r, t\right)$. Jadi, terbukti A adalah kompak.

Proposisi 3.5. [5] Misalkan P dan $Q$ adalah dua himpunan kompak di ruang metrik fuzzy, maka $P \cup Q$ adalah kompak.

Bukti. Misalkan $P$ dan $Q$ adalah himpunan kompak di ruang metrik fuzzy, maka $P \subseteq \bigcup_{p_{i} \in P} B_{M}\left(p_{i}, r, t\right)$ dan $Q \subseteq \bigcup_{q_{i} \in Q} B_{M}\left(q_{i}, r, t\right)$, untuk setiap $r \in(0,1), t>0$ dan $i=1,2, \cdots, n$ sehingga $P \cup Q \subseteq\left(\bigcup_{p_{i} \in P} B_{M}\left(p_{i}, r, t\right)\right) \cup\left(\bigcup_{q_{i} \in Q} B_{M}\left(q_{i}, r, t\right)\right)$. Misalkan $C=P \cup Q$, maka $C \subseteq \bigcup_{c_{i} \in C} B_{M}\left(c_{i}, r, t\right)$, untuk setiap $r \in(0,1), t>0$ dan $i=1,2, \cdots, n$. Terbukti $P \cup Q$ adalah himpunan kompak.

Akibat 3.6. [5] Misalkan P himpunan berhingga dan $Q$ adalah himpunan kompak di ruang metrik fuzzy maka $P \cup Q$ adalah kompak. 
Bukti. Berdasarkan Teorema 3.4 maka $P$ adalah himpunan kompak di ruang metrik fuzzy. Berdasarkan Proposisi 1, jelaslah $P \cup Q$ adalah himpunan kompak. $\square$

Definisi 3.7. [5] (X, M,*) dikatakan ruang metrik fuzzy kompak barisan jika setiap barisan di $X$ memiliki subbarisan konvergen ke suatu titik di $X$.

Contoh 3.8. [5] Misalkan $(X, d)$ adalah ruang metrik dimana $X=[0,1]$ dan $d$ adalah metrik Euclidean di $X$. Misalkan $*_{L}$ adalah norm-t kontinu dengan $a *_{L} b=$ $\max \{a+b-1,0\}$. Didefinisikan himpunan fuzzy $M$ pada $X \times X \times[0, \infty)$ dengan kondisi berikut.

$$
M(x, y, t)= \begin{cases}0, & \text { jika } t=0 \\ 1-d(x, y), & \text { jika } 0<t \leq 1 \\ 1, & \text { jika } t>1\end{cases}
$$

untuk setiap $x, y \in X$ dan $t>0$. Maka $(X, M, *)$ adalah ruang metrik fuzzy kompak barisan.

Teorema 3.9. [5] Misalkan $(X, M, *)$ adalah ruang metrik fuzzy dan $A \subseteq X$, maka $A$ adalah kompak jika dan hanya jika setiap barisan memiliki subbarisan konvergen ke titik di $X$.

Bukti. $(\Rightarrow)$ Misalkan $\left(x_{n}\right)$ adalah sebarang barisan di $A$ dan $\left(x_{n_{k}}\right)$ adalah subbarisan dari $\left(x_{n}\right)$. Karena $A$ kompak, maka terdapat selimut buka $\left\{B_{M}(x, r, t)\right.$ : $x \in A\}$ di $A$ dan subselimut berhingga $\left\{B_{M}\left(x_{i}, r, t\right): x_{i} \in A\right\}$ dengan $r \in$ $(0,1)$ dan $t>0$. Selanjutnya, misalkan untuk setiap $r_{1} \in(0,1)$ dan $\frac{t}{3}>0$. Karena $\left(x_{n_{k}}\right)$ adalah subbarisan dari $\left(x_{n}\right)$ dan $\left(x_{n}\right) \in B_{M}(x, r, t)$ untuk beberapa $x \in A$, maka $r_{1}<r$. Perhatikan bahwa untuk setiap $r_{1}<r$ terdapat $r_{0}$ sehingga $r_{1}<r_{0}<r$. Dengan menggunakan kondisi 4 pada Definisi 2.4, diperoleh $M\left(x_{n_{k}}, x, t\right)>1-r$. Hal ini sesuai dengan pernyataan Maggie Aphane dalam [3] bahwa untuk setiap $r_{1}>r_{2}$, terdapat suatu $r_{3}$ sehingga $r_{1} * r_{3} \geq r_{2}$ dan untuk setiap $r_{4}$, terdapat suatu $r_{5}$ sehingga $r_{5} * r_{5} \geq r_{4},\left(r_{1}, r_{2}, r_{3}, r_{4}, r_{5} \in(0,1)\right)$. Berdasarkan Definisi 2.10, subbarisan $\left(x_{n_{k}}\right)$ dari barisan $\left(x_{n}\right)$ konvergen titik $x \in A$. Terbukti setiap barisan memiliki subbarisan konvergen ke titik di $X$.

$(\Leftarrow)$ Misalkan $A$ bukan himpunan kompak. Misalkan $\left(x_{n}\right)$ adalah sebarang barisan di $A$ dan $\left\{B_{M}(x, r, t): x \in A\right\}$ adalah selimut buka di $A$ sehingga $A \subseteq \bigcup_{x \in A} B_{M}(x, r, t)$. Karena $\left(x_{n}\right) \in A$ maka $\left(x_{n}\right) \in \bigcup_{x \in A} B_{M}(x, r, t)$ sehingga $M\left(x_{n}, x, t\right)>1-r$. Selanjutnya, misalkan $\left(x_{n_{k}}\right)$ adalah subbarisan dari $\left(x_{n}\right)$ dan terdapat subselimut berhingga $\left\{B_{M}\left(x_{i}, r, t\right): x_{i} \in A, i=1,2, \cdots, n\right\}$, tetapi $A \nsubseteq$ $\bigcup_{i=1}^{n} B_{M}\left(x_{i}, r, t\right)$ sehingga $\left(x_{n_{k}}\right) \notin \bigcup_{i=1}^{n} B_{M}\left(x_{i}, r, t\right)$ dan jelas $\left(x_{n_{k}}\right) \notin B_{M}\left(x_{i}, r, t\right)$ untuk beberapa $x_{i} \in A$ sehingga $M\left(x_{n_{k}}, x_{i}, t\right) \leq 1-r$, untuk beberapa $x_{i} \in A \subseteq X$. Terbukti bahwa terdapat barisan yang memiliki subbarisan yang tidak konvergen ke titik di $X$.

Teorema 3.10. [5] Pada ruang metrik fuzzy, setiap subhimpunan tertutup pada himpunan kompak adalah kompak. 
Bukti. Misalkan $X$ himpunan kompak pada ruang metrik fuzzy dan $A \subset X$ dengan $A$ subhimpunan tertutup dari $X$. Dari Definisi 2.13, suatu subhimpunan $A$ dari $X$ dikatakan tertutup jika untuk setiap barisan $\left(x_{n}\right)$ di $A$ konvergen ke $x \in A$. Misalkan $\left(x_{n_{k}}\right)$ adalah subbarisan dari barisan $\left(x_{n}\right)$, maka setiap subbarisan $\left(x_{n_{k}}\right)$ konvergen. Dari Teorema 3.7, subhimpunan $A$ adalah kompak jika dan hanya jika setiap barisannya memiliki subbarisan konvergen ke titik di $X$. Jadi, jelas bahwa setiap subhimpunan tertutup dari himpunan kompak adalah kompak.

Teorema 3.11. [5] Misalkan $\left(x_{n}\right)$ adalah barisan cauchy di suatu himpunan kompak $A$ di ruang metrik fuzzy, maka terdapat $x \in A$ sehingga $x_{n} \rightarrow x$.

Bukti. Misalkan $\left(x_{n}\right)$ adalah barisan Cauchy di himpunan kompak $A$. Karena $A$ adalah himpunan kompak maka $\left(x_{n}\right) \in B_{M}\left(x_{i}, r, t\right)$ untuk beberapa $x_{i} \in A$. Anggap $\left(x_{n}\right)$ tidak konvergen ke $x$, maka $M\left(x_{n}, x, t\right) \leq 1-r$, untuk setiap $r \in(0,1)$ dan $t>$ 0. $\left(x_{n}\right)$ adalah barisan Cauchy maka (berdasarkan Definisi 2.12) untuk setiap $r_{1} \in$ $(0,1), t>0$ terdapat $k \in \mathbb{N}$ sehingga $M\left(x_{n}, x_{m}, \frac{t}{2}\right)>1-r_{1}$, untuk setiap $n, m \geq$ $k$. Berdasarkan Teorema 3.3, maka $A$ terbatas. Misalkan $\left(x_{m}\right)$ adalah sebarang barisan di $A$, maka terdapat $x \in A$ dan untuk setiap $r_{1} \in(0,1), t>0$ sehingga $M\left(x_{m}, x, \frac{t}{2}\right)>1-r_{1}$. Kemudian, dipeoleh $\left(x_{m}\right) \in B_{M}\left(x_{i}, r, t\right)$ untuk beberapa $x_{i} \in A$. Barisan $\left(x_{n}\right)$ dan $\left(x_{m}\right)$ merupakan elemen dari $\bigcup_{i=1}^{n} B\left(x_{i}, r, t\right)$, maka $r_{1}<r$. Perhatikan bahwa untuk setiap $r_{1}<r$, terdapat suatu $r_{0}$ sehingga $r_{1}<r_{0}<r$. Dengan menggunakan kondisi 4 pada Definisi 2.4, diperoleh $M\left(x_{n}, x, t\right)>1-r$. Hal ini sesuai dengan pernyataan Maggie Aphane dalam [3] bahwa untuk setiap $r_{1}>r_{2}$, terdapat suatu $r_{3}$ sehingga $r_{1} * r_{3} \geq r_{2}$ dan untuk setiap $r_{4}$, terdapat suatu $r_{5}$ sehingga $r_{5} * r_{5} \geq r_{4},\left(r_{1}, r_{2}, r_{3}, r_{4}, r_{5} \in(0,1)\right)$. Hal ini kontradiksi dengan $M\left(x_{n}, x, t\right) \leq 1-r$. Jadi, terbukti $\left(x_{n}\right)$ konvergen ke $x \in A\left(x_{n} \rightarrow x\right)$.

Teorema 3.12. [5] Misalkan $\left(X, M_{1}, *\right)$ dan $\left(Y, M_{2}, *\right)$ adalah ruang metrik fuzzy. Misalkan $f$ adalah fungsi dari $\left(X, M_{1}, *\right)$ ke $\left(Y, M_{2}, *\right)$ dan $f: X \rightarrow Y$ adalah fungsi kontinu. Jika $A$ adalah subhimpunan kompak di $X$, maka $f(A)$ adalah subhimpunan kompak di $Y$.

Bukti. Misalkan $\left(X, M_{1}, *\right)$ dan $\left(Y, M_{2}, *\right)$ adalah ruang metrik fuzzy dan $f: X \rightarrow$ $Y$ adalah fungsi kontinu. Karena fungsi $f$ memetakan $X$ ke $Y$, maka fungsi $f$ memetakan $A \subset X$ ke $f(A) \subset Y$. Misalkan $\left(y_{n}\right)$ adalah barisan di $f(A)$, maka untuk setiap $n$ terdapat barisan $\left(x_{n}\right)$ di $A$ sehingga $f\left(x_{n}\right)=y_{n}$.

Karena A adalah himpunan kompak maka terdapat suatu subbarisan $\left(x_{n_{k}}\right)$ di $\left(x_{n}\right)$ dan $x_{0} \in A$ sehingga $\left(x_{n_{k}}\right)$ konvergen ke $x_{0}$ di $A$. Karena $f$ kontinu di $x_{0} \in A$, berdasarkan Definisi 2.15, jika untuk setiap $r \in(0,1)$ dan $t>0$ terdapat $r_{1} \in$ $(0,1)$ dan $s>0$ sehingga untuk semua $x \in X$, diperoleh: $M\left(x_{n_{k}}, x_{0}, s\right)>1-r_{1}$ maka $M\left(f\left(x_{n_{k}}\right), f\left(x_{0}\right), t\right)>1-r$. Dengan kata lain, karena $f\left(x_{n_{k}}\right)=y_{n_{k}}$ maka $M\left(y_{n_{k}}, f\left(x_{0}\right), t\right)>1-r$, untuk semua $k \geq n$. Jadi, $f(A)$ adalah subhimpunan kompak di Y. 


\section{Kesimpulan}

Berdasarkan pembahasan di atas, kesimpulan yang diperoleh, yaitu:

(1) Suatu himpunan disebut himpunan kompak pada ruang metrik fuzzy jika setiap selimut bukanya memiliki subselimut berhingga.

(2) Setiap subhhimpunan kompak $A$ di suatu ruang metrik fuzzy adalah terbatas.

(3) Setiap himpunan berhingga pada ruang metrik fuzzy adalah kompak.

(4) Gabungan dari himpunan-himpunan kompak di ruang metrik fuzzy adalah kompak.

(5) Gabungan himpunan berhingga dan himpunan kompak di ruang metrik fuzzy adalah kompak.

(6) Suatu ruang metrik fuzzy $(X, M, *)$ disebut ruang metrik fuzzy kompak barisan jika setiap barisannya memiliki subbarisan yang konvergen ke suatu titik di $X$.

(7) Suatu himpunan disebut himpunan kompak pada ruang metrik fuzzy $(X, M, *)$ jika dan hanya jika setiap barisannya memiliki subbarisan konvergen ke titik di $X$.

(8) Pada ruang metrik fuzzy, setiap subhimpunan tertutup pada himpunan kompak adalah kompak.

(9) Suatu barisan Cauchy pada suatu himpunan kompak $A$ di ruang metrik fuzzy merupakan barisan yang konvergen ke suatu titik di $A$.

(10) Misalkan $f: X \rightarrow Y$ adalah fungsi kontinu yang menghubungkan dua ruang metrik fuzzy. Jika $A$ adalah subhimpunan kompak di $X$, maka $f(A)$ adalah subhimpunan kompak di $Y$.

\section{Ucapan Terima Kasih}

Penulis mengucapkan terima kasih kepada Dr. Shelvi Ekariani, Dr. Admi Nazra, dan Efendi, M.Si yang telah memberikan kritikan, saran dan masukan sehingga tulisan ini dapat diselesaikan dengan baik.

\section{Daftar Pustaka}

[1] Bartle, Robert G, Donald R. Sherbert. 2010. Introduction To Real Analysis (Fourth Edition).USA: John Wiley \& Sons, Inc.

[2] Davidson, Kenneth R, Allan P. Donsig. 2010. Real Analysis and Applications Theory in Practice. USA: Springer.

[3] Aphane, Maggie. 2009. "On Some Results of Analysis In Metric Space And Fuzzy Metric Space" (Disertasi). University of South Africa.

[4] A, Sapena. 2001. A Contribution To The Study of Fuzzy Metric Spaces. Applied General Topology Vol.2, No.(1), pp (63-75).

[5] Al-Mayahi, Noori F, Sarim H. Hadi. 2014. Some New Result of Compact Sets In Fuzzy Metric Space. Journal of Al-Qadisiyah For Computer Science And Mathematics Vol.6, No.(2).

[6] Li, Cahngqing, Kedian Li. 2017.On Topological Properties of Hausdorff Fuzzy Metric Space. Filomat. Vol.31, No.5, pp (1167-1173).

[7] Zadeh, L.A. 1965. Fuzzy Set. Information and Control. Vol.8, pp (338-353). 